\title{
Castability tests applied to an aluminium-copper alloy
}

\author{
B. GARDA, L. FORTIN and F. DURAND
}

INP de Grenoble, Madylam, URA 1326 du CNRS, BP. 95, 38402 Saint Martin d'Hères, France

\begin{abstract}
Simplified castability tests were performed on an Al-2\%Cu alloy. Measured values of the fluid length can be represented by Ragone's model, giving an estimate for the metal-mould heat transfer coefficient. The grain structure can be considered as a case of columnar-toequiaxed transition in relatively simple flow conditions.
\end{abstract}

\section{INTRODUCTION}

The castability test is currently used in order to measure ability of a metal to fill thin and slender foundry component parts. The liquid metal is injected by suction into a mould print in a shape of a rod. The castability is measured by the fluid length that the liquid has run before it is stopped by solidification. The paper is oriented to the heat transfer between metal and mould, and to the solidification grain structure.

\section{EXPERIMENTAL DEVICE AND PROCEDURE}

In the present state, the mould is a simple low cost tube of mild steel. Its end is connected to a low pressure reservoir $(0.7 \mathrm{~atm}$ pressure drop in the present program), via an electrical gate. 3 thermocouples (K-type) are fixed symetrically by brazing at $20 \mathrm{~cm}$ from the inlet on the external surface of the tube. A second thermocouple triplet is fixed $20 \mathrm{~cm}$ farther. Another K-thermocouple is dipped directly in the liquid, just at the tube inlet. This latter gives the casting temperature $T_{c}$. Thermocouple voltage is recorded by a high rate data logger, operating at $1250 \mathrm{~Hz}$.

The alloy is prepared from aluminium, alloyed with copper ( $2 \%$ in weight). Aluminium is technically pure, it contains $0.10 \% \mathrm{Si}$ and $0.30 \% \mathrm{Fe}$ as impurities. The metals are melted by induction in a ceramic crucible. The mould-tube is positionned vertically above the crucible, the mould inlet being at $4 \mathrm{~cm}$ approximately from the melt surface. When the temperature is at $20^{\circ} \mathrm{C}$ above the chosen $\mathrm{T}_{\mathcal{C}}$, data acquisition starts, the mould-tube is mechanicaly dipped into the melt. A control switch stops the tube entry at $4 \mathrm{~cm}$ approximately under the melt surface, it opens the gate which links the tube to the vacuum reservoir, so the liquid is sucked into the mould. Simultaneously a signal is recorded by the data unit.

The liquid flow is very short, half a second or less, and the metal is rapidly frozen. After, the tube is removed from the melt, the cast rod is extracted, its external surface is examined, possible voids are noted. Then metallographic examinations are performed.

The casting parameters are the pressure drop (presently $0.7 \mathrm{~atm}$ ), the internal diameter of the tube $(5$ and $6 \mathrm{~mm})$, its external diameter $(10 \mathrm{~mm})$ and the casting temperature, ranging from 670 to $780^{\circ} \mathrm{C}$.

Present results are the fluid length $L_{f}$, initial velocity $V_{0}$, mean velocity $V_{m}$, temperature records, casting surface morphology and grain structure. 
For metallographical examination, samples are first annealed $\left(1 \mathrm{~h} 30\right.$ at $500^{\circ} \mathrm{C}$ in a salt melt). Macrographs are made from longitudinal cuts, polished, then etched (Sperry etchant). In order to reveal the equiaxed grain size, samples are submitted to anodic oxidation. Color micrographs are taken under polarized light. A black-and-white tracing of the grain contours is taken by hand, then it is treated by digital image analysis

\section{RESULTS AND DISCUSSION}

The temperature records give informations on the movement of the liqiud front, in particular its initialvelocity $V_{0}$, and its mean velocity $V_{m}$. The fluid length $L_{f}$ varies with the casting temperature Tc, and with the tube internal radius $r_{0}$. A simple thermal model, initially proposed by Portevin and Bastien [1] then improved by Ragone, McAdams, and Taylor [2] takes these 2 parameters into account. It is assumed that heat transfer between metal (at temperature $\mathrm{T}_{\mathrm{C}}$ ) and mold (at temperature $T_{a}$ ) is controlled by a newtonian heat transfer coefficient $h$. The fluid time $q_{F}$ is considered as the sum of 2 terms, q1 and q2, corresponding to the extraction of superheat, and of latent heat, respectively.

$$
\begin{aligned}
& \theta F=\frac{L f}{V}=\theta 1+\theta 2 \\
& \theta 1=\frac{r_{O} \rho C_{p}}{2 h} \frac{T_{c}-T_{e q}}{T_{e q}-T_{a}} \\
& \theta 2=\frac{r_{O} \rho \Delta H F}{2 h\left(T_{e q}-T_{a}\right)}
\end{aligned}
$$

Therefore all experiment can be represented on a linear plot (Fig.1). The slope gives $\mathrm{h}=7100 \pm 400 \mathrm{~W} \mathrm{~m}^{-2} \mathrm{~K}^{-1}$. This value can be compared with $\mathrm{h}$ values recently published by Schmidt [3] , concerning low pressure die casting in a tool steel tube for on alloy AlSi7Mg, he gives a value increasing from 2000 to $5000 \mathrm{~W} \mathrm{~m}^{-2} \mathrm{~K}^{-1}$ during the 4 first seconds after injection. For an alloy AlSi12, h increases from 2800 to more than $8000 \mathrm{~W} \mathrm{~m}^{-2} \mathrm{~K}^{-1}$. In fact, the comparaison should be made only whith the initial values, representative of the fluid regime. Moreover, Schmidts's result depends strongly on the alloy composition.

The solidification structure of the cast rods shows 3 parts (Fig.2). The main characteristics were already mentionned by Flemings [4]. The first part is entirely columnar. From section $\mathrm{AA}^{\prime}$ to section BB', equiaxed grains appear in the central part, and progressively invade the cross section. At first look, columnar grains seem to be thinner when the distance to the inlet increases. Besides, they are clearly tilted with respect to the mould, and oriented at countercurrent with respect to the liquid flow. The final part, up to the metal/atmosphere front, is entirely equiaxed. The equiaxed crystals are very fine everywhere, excepted one or two zones of coarse grains occupying the cross section. Apart from these zones, measured values of the grain size are ranging from 40 to $50 \mu \mathrm{m}$, it means a relatively uniform value.

In conclusion, the simplified castability test applied to this $\mathrm{Al}-2 \% \mathrm{Cu}$ alloy gives a solidification grain structure relatively easy to describe. The frontier between equiaxed and columnar zones is geometrically simple. The equiaxed grain size is relatively uniform. Castability experiments should be a good field to test current models for nucleation and growth phenomena, and to form a database on solidification structure of thin castings. 


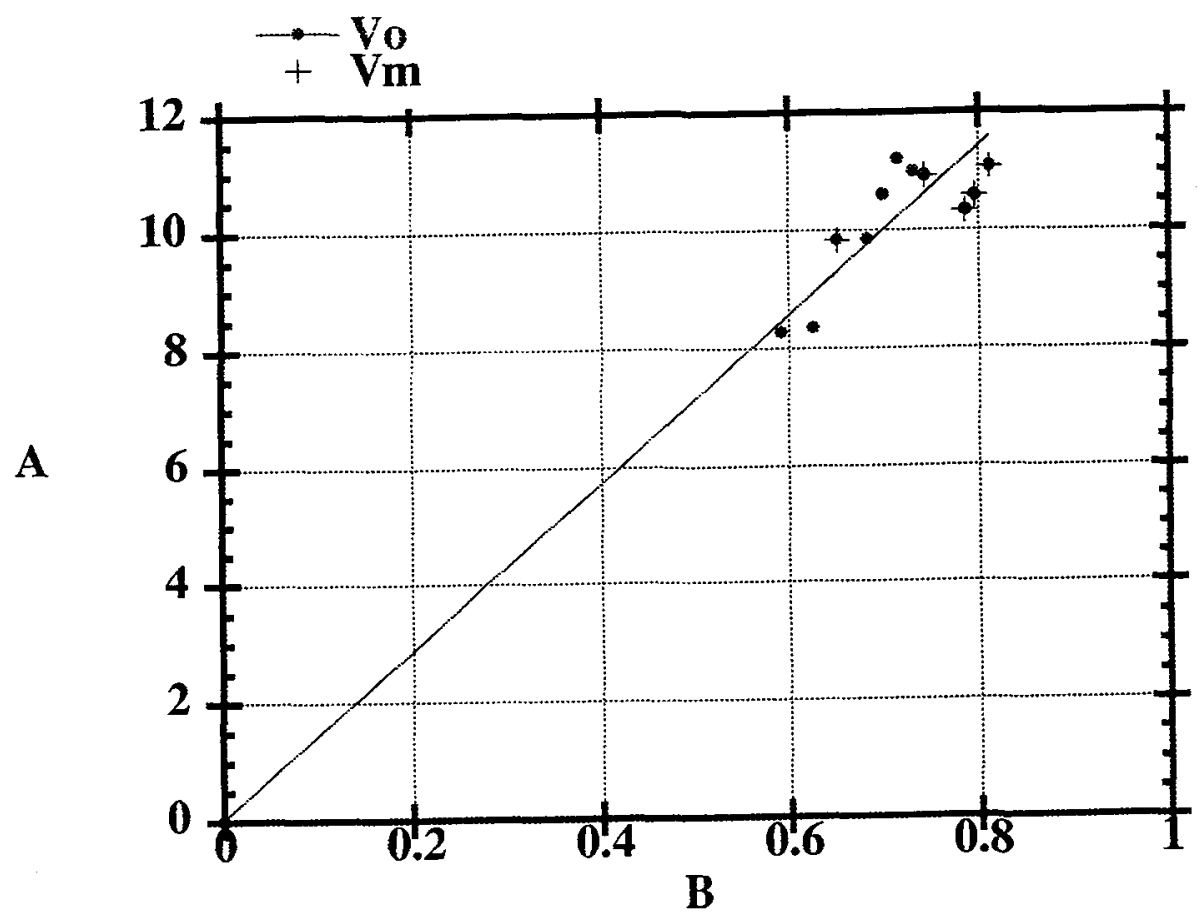

Figure 1: Experimental determination of $h$ value

$$
A=\frac{2 \mathrm{Lf}}{\mathrm{r} 0 \mathrm{~V} \rho \mathrm{C}_{\mathrm{p}}} 10^{+5} \quad \mathrm{~B}=\frac{\mathrm{T}_{\mathrm{C}}-\mathrm{T}_{\mathrm{eq}}}{\mathrm{T}_{\text {eq }}-\mathrm{T}_{\mathrm{a}}}+\frac{\Delta \mathrm{HF}}{\mathrm{C}_{\mathrm{p}}\left(\mathrm{T}_{\text {eq }}-\mathrm{T}_{\mathrm{a}}\right)}
$$

\section{ACKNOWLEDGMENT}

The authors gratefully acknowledge the financial support of the European Community authorities, under contract Brite Euram $0262 \mathrm{M}$, entitled "Convective Effects in Solidification".

\section{REFERENCES}

[1] PORTEVIN A., BASTIEN P., Comptes Rendus Acad.Sci.Paris (1932), 599-601:

[2] RAGONE D.V., MCADAMS C., TAYLOR H.F., A.F.S Trans (1956), vol 64, 640.

[3] SCHMIDT P., E-MRS Conf Strasbourg (1993), to be published in Mat.Sci.Eng.

[4] FLEMINGS M.C., Brit Foundryman 57 (1964), 312-325. 

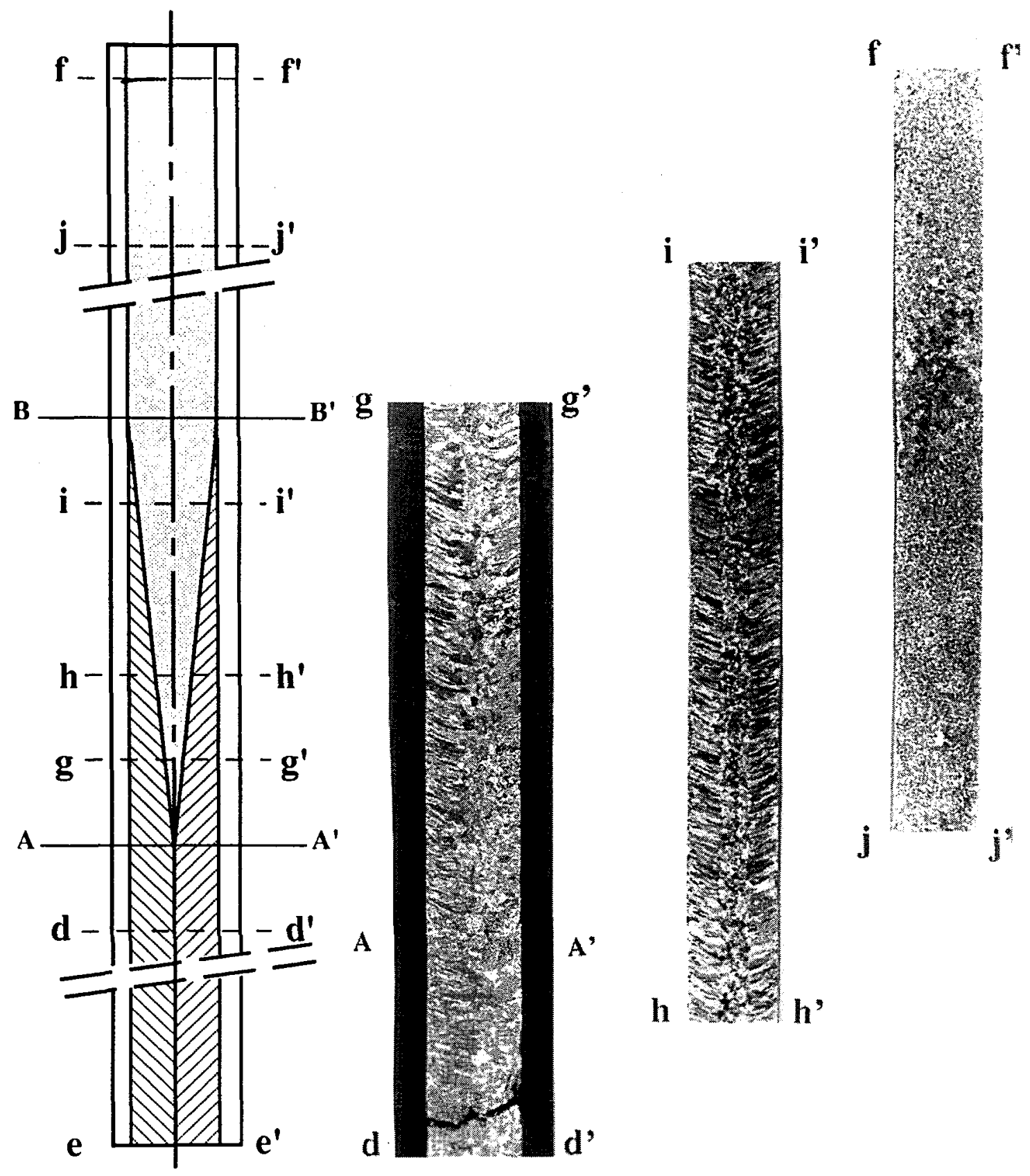

Figure 2: Macrograph of the cast rod ee' is the metal entry, ff' is the metal front 